\title{
Molecular epidemiology of human sporotrichosis in Venezuela reveals high frequency of Sporothrix globosa
}

Emma Camacho ${ }^{1}$, Isabel León-Navarro ${ }^{1}$ Sabrina Rodríguez-Brito ${ }^{1}$, Mireya Mendoza ${ }^{2}$ and Gustavo A Niño-Vega ${ }^{\text {* }}$

\begin{abstract}
Background: Sporotrichosis is a cutaneous and subcutaneous fungal disease of humans and other mammals, known to be caused by the Sporothrix schenckii species complex, which comprises four species of clinical importance: S. brasiliensis, S. globosa, S. luriei, and S. schenckii sensu stricto. Of them, S. globosa and S. schenckii s. str. show global distribution and differences in global frequency as causal agents of the disease. In the Americas, only three species are present: S. schenckii s. str., S. brasiliensis (so far, only reported in Brazil), and S. globosa. In Venezuela, since the first case of sporotrichosis reported in 1935, S. schenckii have been considered its unique etiological agent. In the present work, the presence of more than one species in the country was evaluated.

Methods: By phenotypic key features and molecular phylogeny analyses, we re-examined 30 isolates from diverse Venezuelan regions belonging to the fungi collection of Instituto de Biomedicina, Caracas, Venezuela, and national reference center for skin diseases. All isolates were collected between 1973 and 2013, and maintained in distilled water.

Results: Sporotrichosis in Venezuela is mainly caused by S. schenckii s. str. (70\%). However, a significant proportion (30\%) of sporotrichosis cases in the country can be attributable to S. globosa. A correlation between intraspecific genotypes and clinical presentation is proposed.

Conclusions: Our data suggest that sporotrichosis various clinical forms might be related to genetic diversity of isolates, and possibly, to diverse virulence profiles previously reported in the S. schenckii species complex. Sporothrix globosa was found to be the causative agent of $30 \%$ of sporotrichosis for the Venezuelan cases re-examined, the highest frequency of this species so far reported in the Americas. The high genetic variability presented by $S$. schenckii s. str. indicates that species distinction based on phenotypic key features could be a challenging and uncertain task; molecular identification should be always employed.
\end{abstract}

Keywords: Sporothrix schenckii species complex, Sporothrix globosa, Sporotrichosis, Clinical forms, Phenotypic identification, Phylogenetic analysis, American continent, Venezuela

\section{Background}

Over the last few years, the Sporothrix schenckii species complex (formerly known as S. schenckii) has received special interest due to the increasing number of infections caused by it worldwide, particularly in immunocompromised patients [1], and epidemic outbreaks in cats in Brazil [2]. It is responsible for sporotrichosis, a

\footnotetext{
* Correspondence: gnino@ivic.gob.ve

${ }^{1}$ Centro de Microbiología y Biología Celular, Instituto Venezolano de Investigaciones Científicas, Caracas, Venezuela

Full list of author information is available at the end of the article
}

chronic granulomatous subcutaneous mycosis of humans and other mammals. Primary infection has been reported as caused by traumatic inoculation of environmental material carrying saprophytic hyphae and conidia of the etiologic agents $[2,3]$. Once into the warm-blooded host, these dimorphic fungi are capable to convert into pathogenic yeasts, causing infections that range from fixed cutaneous localized lesions to severe disseminated sporotrichosis [3-5]. However, zoonotic transmission is also possible, by scratches or bites from asymptomatic or infected animals, with cats being the main vectors through which the 
disease is transmitted to humans or other animals [6-8]. The last makes direct inoculation of pathogenic yeast a plausible source of infection. Although the disease has a global occurrence, endemic areas are mostly located in tropical and subtropical countries [6,9]; furthermore, Sporothrix infections may take epidemic proportions $[7,8,10]$ and its distinct etiological agents differ in virulence profiles [11-13], antifungal susceptibility [14,15], and geographic distribution [16].

Molecular phylogenetic analyses have led to description of at least four cryptic species of clinical relevance within the $S$. schenckii species complex, comprising $S$. brasiliensis, S. schenckii sensu stricto (s. str), S. globosa and S. luriei [2,8,17-19]. Scattered reports of Sporothrix spp. outside these four clades, causing clinical cases have been published, such as $S$. mexicana $[16,20]$ and $S$. pallida [21], or by close relatives in the genus Ophiostoma, i.e. O. piceae [22] and O. stenoceras [23]. However, these species appear to lack human-pathogenic potential, thus they are proposed to be accidentally pathogenic [17]. Besides molecular phylogeny, morphological and physiological key features have been proposed for species recognition within the Sporothrix species complex [18,19].

In Venezuela, sporotrichosis is the second most common subcutaneous mycosis after chromomycosis. It was first described in 1935, nevertheless the exact prevalence in the country is unknown [24]. According to conventional mycological procedures, as well as epidemiological data, all isolates related to sporotrichosis have been identified as Sporothrix schenckii.

The aim of the present study was to determine if, besides S. schenckii, other Sporothrix species of the complex might be present in the country. We re-examined 30 isolates, by phenotypic and molecular methods, discovering that $S$. globosa was the etiological agent in one third of the cases.

\section{Methods}

\section{Fungal isolates and strains used}

Thirty isolates (29 clinical and 1 environmental) from different Venezuelan regions (Coastal range; $n=22$, The Andes; $n=7$; The Plains; $n=2$ ) were examined in this study (Table 1). All isolates were previously identified as S. schenckii by means of morphology (macro and microscopic studies), ability of isolates to reverse to yeast-like cells at $37^{\circ} \mathrm{C}$, and serological tests to patients from where they were isolated, all performed in the Mycology Laboratory at Instituto de Biomedicina, Caracas, Venezuela, a national reference center for skin diseases. Isolates were taken as part of standard patient care, and no ethical approval was required for their use. They have been kept as part of the laboratory fungal collection over a period of 40 years (from 1973 to 2013) and were selected for inclusion in this study based on their geographic distribution.
They were preserved in distilled water (Castellani's method), and recovered by growth on Sabouraud dextrose agar (SDA) complemented with $150 \mu \mathrm{g} \mathrm{ml}^{-1}$ chloramphenicol at room temperature during 7 days. As reference, strains S. schenckii s. str. ATCC-MYA 4820, and S. brasiliensis ATCC-MYA 4823 (provided by Dr. L. Bezerra, Universidade do Estado do Rio de Janeiro, Brazil), as well as S. pallida CBS $302.73^{\mathrm{T}}$, S. globosa FMR 9023, and S. mexicana FMR 9108 kindly provided by Dr. J. Cano (Reus, Spain) were used.

\section{Phenotypic characterization}

Isolates were phenotypically identified according to Marimon et al. [18]. Macroscopic features of colonies were studied by culturing isolates on potato dextrose agar (PDA, HIMEDIA, India) plates, incubated at room temperature (growth control), $30^{\circ} \mathrm{C}$ and $37^{\circ} \mathrm{C}$ in dark. Petri dishes $(90 \times 15 \mathrm{~mm}$, with $8 \mathrm{~mm}$ PDA) were centrally inoculated with portions of the colonies of the fungi, approximately $1 \mathrm{~mm}$ in diameter, and incubated upside down. After 14 and 21 days, colony diameters (in millimeters) were measured in duplicate for growth temperatures of $30^{\circ} \mathrm{C}$ and $37^{\circ} \mathrm{C}$, and the mean of the recorded measured diameters taken for final analysis. Microscopic features of conidia were found to be the same for reference strains and a sample of Venezuelan isolates when lactrimel agar (LA) was used instead of the corn meal agar (CMA) used by Marimon et al. [18]. So for the rest of the study, microscopic features of conidia were determined from slide cultures made on lactrimel agar (10 g honey, $20 \mathrm{~g}$ wheat flour, $200 \mathrm{ml}$ milk, $9.5 \mathrm{~g}$ agar, $800 \mathrm{ml}$ distilled water and $150 \mu \mathrm{g} \mathrm{ml}^{-1}$ chloramphenicol) after 12-15 days of incubation in the dark in a humid chamber. Coverslips were mounted in lactophenol cotton blue $(0.05 \%(\mathrm{w} / \mathrm{v})), 2 \%$ phenol, $2 \%$ lactic acid and $4 \%$ glycerin), and examined under a light microscope (Leica DM2000) at 40X and 100X. Carbohydrate assimilation tests for sucrose and raffinose were conducted in 96-well microplates, using $150-\mu \mathrm{l}$ of a working solution composed of yeast nitrogen base (YNB) medium (SigmaAldrich, USA) with corresponding test sugar, or plain (only base medium), as described by Marimon et al. [18]. Briefly, the isolates were grown on potato dextrose broth for 7 days at $23^{\circ} \mathrm{C}$, or on Brain-Heart Infusion agar (BHI, OXOID, England), at $30^{\circ} \mathrm{C}$ for isolates that did not sporulated with the previous conditions. Conidia were collected by filtering 10 to $20 \mathrm{ml}$ liquid culture through sterile gauze and quantified in a spectrophotometer at $600 \mathrm{~nm}$. Each suspension was adjusted to an optical density that ranged from 0.21 to 0.29 , corresponding to a final inoculum in the microplate of $2 \times 10^{5}$ to $2 \times 10^{6} \mathrm{CFU} / \mathrm{ml}$. Each well was inoculated with $50 \mu \mathrm{l}$ inoculum and $150 \mu \mathrm{l}$ YNB medium with corresponding carbohydrate, at a final concentration of $3.75 \%$. YNB medium without sugar was used as 
Table 1 Isolates used in this study

\begin{tabular}{|c|c|c|c|c|c|}
\hline \multirow[t]{2}{*}{ Isolate } & \multirow{2}{*}{$\begin{array}{l}\text { Species } \\
\text { (by molecular } \\
\text { genotyping) }\end{array}$} & \multirow[t]{2}{*}{ Source } & \multirow[t]{2}{*}{ Origin } & \multicolumn{2}{|c|}{ GenBank Accession $\mathbf{N}^{\circ}$} \\
\hline & & & & CAL & ITS \\
\hline C0014 & S. schenckii & Clinical, Human (lymphocutaneous) & Coastal range (Distrito Capital, Venezuela) & ${ }^{1} \mathrm{KF} 478909$ & ${ }^{1} \mathrm{KJ} 999877$ \\
\hline C0329 & S. globosa & Clinical, Human (fixed cutaneous) & The Andes (Táchira, Venezuela) & ${ }^{1} \mathrm{KF} 478892$ & ${ }^{1} \mathrm{KJ} 999878$ \\
\hline C0596 & S. schenckii & Clinical, Human (fixed cutaneous) & Coastal range (Miranda, Venezuela & ${ }^{1} \mathrm{KF} 478896$ & 'KJ999879 \\
\hline C1163 & S. schenckii & Clinical, Human (lymphocutaneous) & Coastal range (Distrito Capital, Venezuela) & ${ }^{1} \mathrm{KF} 478910$ & ${ }^{1} \mathrm{KJ} 999880$ \\
\hline C2606 & S. schenckii & NA & Coastal range (Distrito Capital, Venezuela) & ${ }^{1} \mathrm{KF} 478887$ & ${ }^{1}$ KJ999881 \\
\hline C2656 & S. schenckii & Clinical, Human (fixed cutaneous) & The Andes (Trujillo, Venezuela) & ${ }^{1} \mathrm{KF} 478897$ & ${ }^{1}$ KJ9998882 \\
\hline C2745 & S. schenckii & Clinical, Human (fixed cutaneous) & The Plains (Monagas, Venezuela) & ${ }^{1} \mathrm{KF} 478891$ & 'KJ9998883 \\
\hline C2888 & S. schenckii & Clinical, Human (lymphocutaneous) & Coastal range (Distrito Capital, Venezuela) & ${ }^{1} \mathrm{KF} 478886$ & ${ }^{1} \mathrm{~K} / 999884$ \\
\hline C3037 & S. schenckii & Clinical, Human (disseminated) & Coastal range (Distrito Capital, Venezuela) & ${ }^{1} \mathrm{KF} 478888$ & ${ }^{1}$ KJ9998885 \\
\hline C3527 & S. schenckii & NA & Coastal range (Distrito Capital, Venezuela) & ${ }^{1} \mathrm{KF} 478898$ & ${ }^{1}$ KJ9998866 \\
\hline C3673 & S. globosa & Clinical, Human (fixed cutaneous) & Coastal range (Distrito Capital, Venezuela) & ${ }^{1} \mathrm{KF} 478892$ & ${ }^{1}$ KJ9998887 \\
\hline C3705 & S. schenckii & Clinical, Human (lymphocutaneous) & Coastal range (Distrito Capital, Venezuela) & ${ }^{1} \mathrm{KF} 478884$ & ${ }^{1} \mathrm{~K} / 999888$ \\
\hline C4346 & S. schenckii & Clinical, Human (lymphocutaneous) & Coastal range (Distrito Capital, Venezuela) & ${ }^{1} \mathrm{KF} 478889$ & ${ }^{1}$ KJ999889 \\
\hline C5000 & S. schenckii & Clinical, Human (lymphocutaneous) & Coastal range (Aragua, Venezuela) & ${ }^{1} \mathrm{KF} 478885$ & ${ }^{1}$ KJ999890 \\
\hline C5859 & S. globosa & Clinical, Human (fixed cutaneous) & Coastal range (Vargas, Venezuela) & ${ }^{1} \mathrm{KF} 478893$ & ${ }^{1}$ KJ9998991 \\
\hline C7012 & S. schenckii & Clinical, Human (lymphocutaneous) & The Andes (Táchira, Venezuela) & ${ }^{1} \mathrm{KF} 478899$ & 'KJ999892 \\
\hline C8213 & O. stenoceras & Clinical, Human (fixed cutaneous) & Coastal range (Distrito Capital, Venezuela) & ${ }^{1} \mathrm{KF} 478913$ & ${ }^{1}$ KJ999893 \\
\hline C8287 & S. schenckii & Clinical, Human (fixed cutaneous) & Coastal range (Distrito Capital, Venezuela) & ${ }^{1} \mathrm{KF} 478900$ & ${ }^{1}$ KJ999894 \\
\hline C8704 & S. schenckii & NA & Coastal range (Distrito Capital, Venezuela) & ${ }^{1} \mathrm{KF} 478890$ & ${ }^{1} \mathrm{~K} 1999895$ \\
\hline C8775 & S. globosa & Clinical, Human (fixed cutaneous) & Coastal range (Aragua, Venezuela) & ${ }^{1} \mathrm{KF} 478901$ & 'KJ999896 \\
\hline C8857 & S. globosa & Clinical, Human (fixed cutaneous) & The Andes (Trujillo, Venezuela) & ${ }^{1} \mathrm{KF} 478902$ & 'KJ999897 \\
\hline C8888 & S. schenckii & Clinical, Human (lymphocutaneous) & The Andes (Trujillo, Venezuela) & ${ }^{1} \mathrm{KF} 478903$ & ${ }^{1}$ KJ999898 \\
\hline C8962 & S. globosa & Clinical, Human (fixed cutaneous) & The Plains (Cojedes, Venezuela) & ${ }^{1} \mathrm{KF} 478904$ & ${ }^{1}$ KJ999899 \\
\hline C8981 & S. globosa & Clinical, Human (fixed cutaneous) & The Andes (Mérida, Venezuela) & ${ }^{1} \mathrm{KF} 478905$ & ${ }^{1}$ KJ9999000 \\
\hline C9254 & S. globosa & Clinical, Human (fixed cutaneous) & Coastal range (Distrito Capital, Venezuela) & ${ }^{1} \mathrm{KF} 478911$ & ${ }^{1}$ KJ999901 \\
\hline C9300 & S. schenckii & Clinical, Human (lymphocutaneous) & The Andes (Trujillo, Venezuela) & ${ }^{1} \mathrm{KF} 478906$ & 'KJ999902 \\
\hline C9526 & S. schenckii & NA & Coastal range (Distrito Capital, Venezuela) & ${ }^{1} \mathrm{KF} 478907$ & ${ }^{1}$ KJ999903 \\
\hline C9862 & S. schenckii & Clinical, Human (fixed cutaneous) & Coastal range (Distrito Capital, Venezuela) & ${ }^{1} \mathrm{KF} 478912$ & ${ }^{1}$ KJ999904 \\
\hline C9887 & S. globosa & Clinical, Human (fixed cutaneous) & Coastal range (Distrito Capital, Venezuela) & ${ }^{1} \mathrm{KF} 478908$ & 'KJ999905 \\
\hline A0001 & S. schenckii & Environmental, Soil & Coastal range (Aragua, Venezuela) & ${ }^{1} \mathrm{KF} 478894$ & ${ }^{1} \mathrm{KJ} 999876$ \\
\hline ATCC MYA-4820 & S. schenckii & Clinical, Human & Brazil & ${ }^{2} J F 313361$ & ${ }^{3} \mathrm{JQ070111}$ \\
\hline ATCC MYA-4823 & S. brasiliensis & Feline sporothricosis & Brazil & 2JF313351 & ${ }^{3} \mathrm{JQ070114}$ \\
\hline CBS $302.73^{\top}$ & S. pallida & Environmental & United Kingdom & ${ }^{4} \mathrm{AM} 398396$ & ${ }^{1} \mathrm{KJ} 999906$ \\
\hline FMR 9023 & S. globosa & Clinical, Human & Japan & ${ }^{4}$ AM398393 & ${ }^{1} \mathrm{KJ} 999907$ \\
\hline FMR 9108 & S. mexicana & Environmental & Mexico & ${ }^{4} A M 398393$ & ${ }^{5} \mathrm{FN} 549906$ \\
\hline
\end{tabular}

Previously genotyped strains used as reference, in bold.

${ }^{1}$ This study; ${ }^{2}$ Teixeira, M. and Lopes-Bezerra, L.M., direct submission; ${ }^{3}$ Suh, S.-O. and Zhou, J.J, direct submission; ${ }^{4}$ ATCC Mycology Authentication Project.

${ }^{5}$ Madrid et al. [33]. NA, data non-available.

negative control, and with glucose as positive control. Microplates were read at 5 and 10 days of incubation at $25^{\circ} \mathrm{C}$, experiments were conducted by duplicate. The viability of the conidia was verified by plating $20 \mu \mathrm{l}$ of a 1:500 dilution of each inoculum onto YPD (0.5\% yeast, $0.5 \%$ peptone, $1.5 \%$ dextrose) plates. In case of discordant results, experiments were repeated at least two additional times on different days.

\section{Molecular characterization}

Total genomic DNA was isolated from 3-day-old mycelial cultures grown on YPD broth, following the protocol 
described in [25]. Partial amplification of the calmodulin (CAL) locus was obtained by using degenerated primers CL1 and CL2A [26], amplifying a region corresponding to exons 3 through 5 of the CAL gene. ITS regions were amplified from genomic DNA with universal primers ITS5 and ITS4 as described by Zhou et al. [17]. Following PCR, amplicons were purified with the CONCERT ${ }^{\mathrm{m}}$ Rapid PCR purification system (Life Technologies, USA) and sent for sequencing on both strands to Macrogen Inc (Seoul, Korea), with the same primers used for PCR. Assembly of the sequences was done with the Contig program within the Vector NTI suite (Vector NTI, InforMax, Inc, USA). Homology searches were performed on GenBank database using BLAST [27]. The newly reported sequences generated in this study were deposited in the GenBank/EMBL/DDBJ database under accession numbers listed in Table 1.

\section{Phylogenetic analysis}

Sporothrix-calmudulin-related and Sporothrix-ITS-related sequences, previously reported to be obtained with the same two sets of primers here used, were retrieved from Genbank and included in the analyses (Figures 1 and 2) $[16,18]$. As an outgroup, the saprophytic fungus Grosmannia serpens (Ophiostomataceae) [28] was included for the CAL analysis. The multiple nucleotide sequence alignment was performed using the ClustalW algorithm implemented in MEGA5.2 software [29]. Evolutionary analyses were also conducted in MEGA5.2 as described by Rodrigues et al. [16].

\section{Genetic variation analysis}

To evaluate genetic variation, the CAL locus was used as nuclear marker. Nucleotide $(\pi)$ and haplotype $(\mathrm{Hd})$ diversities [30] were estimated using DnaSP software, version 5.10.01 [31]. Sites containing gaps and missing data were not considered in the analysis.

\section{Results}

A total of 30 previously identified S. schenckii Venezuelan isolates (29 clinical and 1 environmental) (Table 1) were re-examined on the basis of phenotypic key features (i.e. growth at various temperatures, macroscopic and microscopic features, and carbohydrate assimilation, according to Marimon et al. [18]), as well as molecular phylogeny inferred from CAL and ITS sequences. Based on the result obtained for reference strain S. globosa FMR 9023 (Table 2), restricted growth at $37^{\circ} \mathrm{C}$ was set at $\leq 6.4 \mathrm{~mm}$ colony diameter (maximum diameter reached in our study by this reference strain, previously identified by Marimon et al. [18]). Only 8 out of 30 isolates (26.67\%) were clearly identified when the summary of key features for Sporothrix species differentiation, proposed by Marimon et al. [18], was strictly followed (Table 2).
One isolate, S. schenckii C8287, was misidentified by following the phenotypic features solely, requiring molecular genotyping for proper identification; it was labeled as S. globosa due to its restrictive growth at $37^{\circ} \mathrm{C}$, and positive/negative assimilation profile for sucrose and raffinose. The remaining 21 isolates (70.00\%) showed inconclusive results, requiring molecular genotyping for proper identification (Table 2). The most ambiguous results (colony growth over $50 \mathrm{~mm}$ diameter at $30^{\circ} \mathrm{C}$ and/or negative assimilation of raffinose) were shown by $S$. schenckii s. str. isolates, for which just 2 out of $20(10 \%)$ were properly identified without the need of molecular phylogeny analysis. However, it is important to notice that when the microscopic features of sessile conidia (pigmentation and morphology) were taken solely, correlation between identification by these features and molecular identification was found (Table 2).

Genotyping of the isolates was performed by using the amplified fragment from the CAL locus. The complete alignment included 90 sequences, 30 generated in this study and 60 retrieved from previous studies, respectively $[16,18]$. The aligned CAL sequences were $595 \mathrm{bp}$ long, including 302 invariable characters, 239 variable parsimony-informative sites $(40.17 \%)$ and 43 singletons. Twenty nine (29) of the 30 Venezuelan isolates clustered within the clinical clades (as defined by previous phylogenetic analyses of Sporothrix spp. based on CAL $[6,16,32])$. Of those 29 isolates, $20(>60 \%)$ grouped as $S$. schenckii s. str., while 9 (30\%) grouped as S. globosa (Figure 1). One isolate (C8213), clustered within the environmental clades as $O$. stenoceras (Figure 1). To corroborate these results, a second phylogenetic analysis was performed, using ITS sequences generated by the universal primers ITS4 and ITS5. Seventy four (74) nucleotide sequences, 30 generated in this study and 44 previously reported [17] were aligned. The aligned ITS sequences were $506 \mathrm{bp}$ long, including 407 invariable characters, 85 variable parsimony-informative sites (16.79\%) and 12 singletons. The Venezuelan isolates were distributed in complete agreement with the CAL-generated phylogeny, with the Venezuelan isolates of $S$. schenckii s. str. and S. globosa (pathogenic species), and O. stenoceras (accidentally pathogenic species) showing strong, statistically supported separation ( $99 \%$ bootstrap) between clinical and environmental clades (Figure 2).

Assessment of the Venezuelan Sporothrix population genetic diversity was explored by using the DnaSP software [31] and CAL as nuclear marker. The haplotype analysis of calmodulin sequences $(n=65)$ divided the isolates into 17 Hap groups. A total of 15 and 5 different types were detected for S. schenckii s. str. and S. globosa, respectively. The majority of haplotypes $(\mathrm{Hd}=0.85)$ belonged to $S$. schenckii s. str., demonstrating a highly 


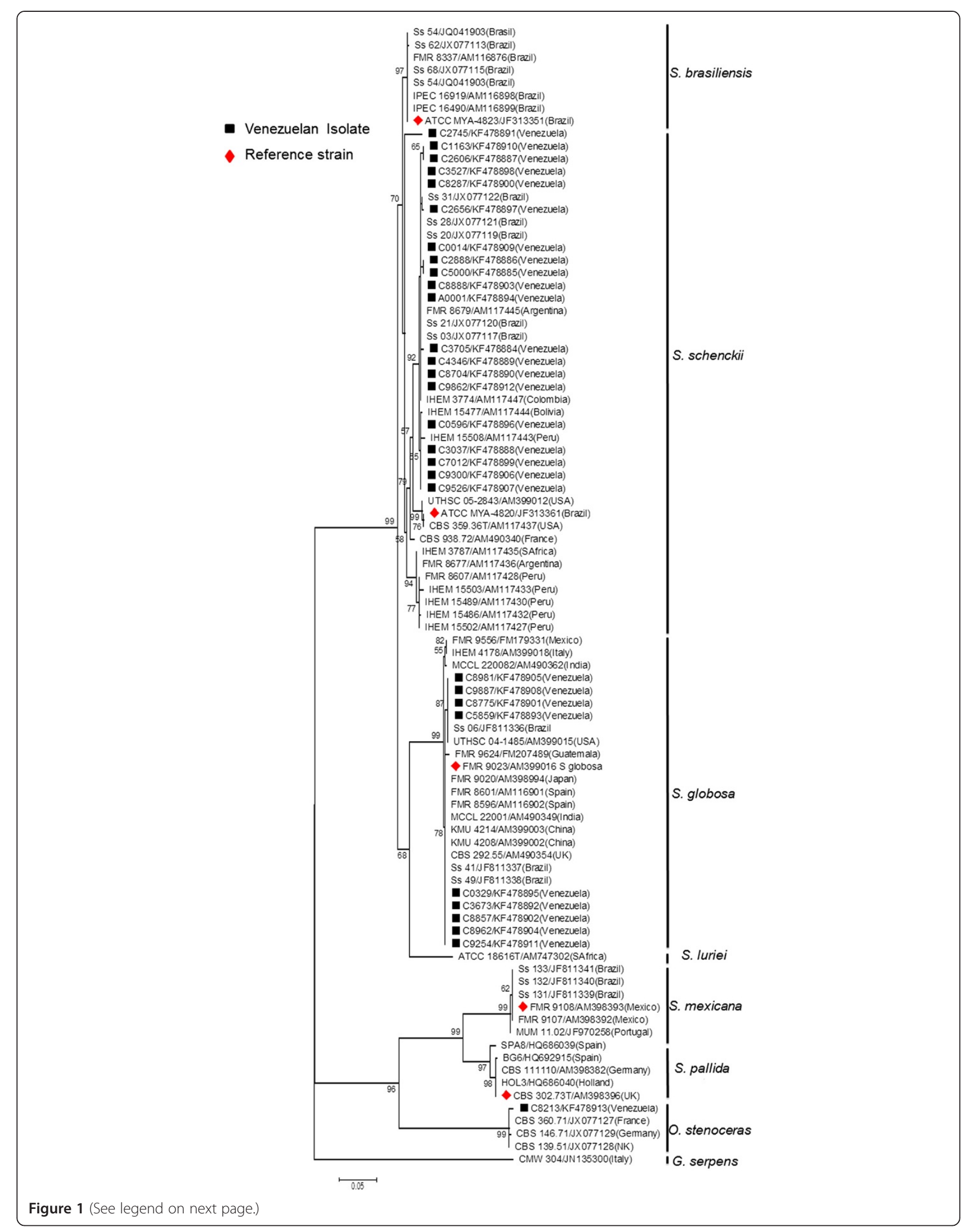


(See figure on previous page.)

Figure 1 Phylogenetic relationships of Sporothrix schenckii complex isolates, inferred from CAL sequences. The phylogenetic tree was built with MEGA 5.1, by the Maximum Likelihood method based on the Kimura 2-parameter model. Thirty sequences from this study and sixty retrieved from previous studies were used for analysis. Number close to branches represents Bootstraps support values based on 1000 bootstrap replications. GenBank accessions numbers are indicated next to strain code in branch labels.

diverse group $(\pi=0.020)$. Meanwhile, $S$. globosa presented low genetic variation $(\mathrm{Hd}=0.59 ; \pi=0.005)$.

According to epidemiological data of clinical cases for the Venezuelan isolates, most of them were geographically restricted to the coastal range region (68.97\%). An analysis of the distribution by gender showed a higher occurrence in male patients (64\%) compared to women (36\%). The most predominant clinical form in this study was fixed cutaneous (60\%), followed by lymphocutaneous (36\%) and one case of disseminated sporotrichosis $(4 \%)$.

An association between clinical forms and phylogenetic species was found (Figure 3). All lymphocutaneous cases $(100 \%)$ were caused by S. schenckii s. str., while fixed cutaneous cases were attributable to both, $S$. schenckii s. str. (33.3\%) and S. globosa (60.0\%), plus a single case by $O$. stenoceras. The only case with disseminated manifestations was related to $S$. schenckii s. str.

\section{Discussion}

Even though sporotrichosis is a cosmopolitan subcutaneous mycosis, the species grouped in the clinical clades have shown a geographical distribution [17]. S. schenckii s. str. presents a frequency over $50 \%$ in America, while $S$. globosa has prevailed in Asia and Europe (56\% and 28\%, respectively), followed by the Americas (11\%) [17]. In the present study, thirty fungal isolates related to sporotrichosis in Venezuela, and previously identified by morphological studies as $S$. schenckii, were characterized by phenotypic key features and molecular phylogeny. The results show that in the country, at least two species are circulating: S. schenckii s. str. and S. globosa. Although S. schenckii s. str. is the main circulating species, with over $60 \%$ of evaluated cases, S. globosa could be considered the second most frequent species causing sporotrichosis in Venezuela. The incidence of S. globosa, with 30\% of cases evaluated, is the highest reported so far in the Americas for this species, and is similar to its reported incidence in Europe [17]. An interesting finding is the fact that all S. globosa isolates here characterized, were related to fixed cutaneous sporotrichosis, which could be related to the low virulence reported for this species $[33,34]$. On the other hand, $100 \%$ of the lymphocutaneous cases, and the single disseminated case were all related to S. schenckii s. str., as well as $33 \%$ of fixed cutaneous sporotrichosis.

In a recent study [13], the virulence profiles of eight $S$. schenckii s. str. were evaluated, and different degrees of virulence were found for this species, from high virulence to non-virulence. High genetic variation have been reported for S. schenckii s. str. [15,33,35]. Here, we also found high genetic variation for the Venezuelan $S$. schenckii s. str. isolates evaluated ( $\mathrm{Hd}=0.85 ; \pi=0.020)$, while low genetic variation was obtained for the $S$. globosa isolates ( $\mathrm{Hd}=0.59 ; \pi=0.005)$. Summing up the preceding results, we could hypothesize that a relationship might be present between the high genetic variation, different clinical presentations, and multiple virulence levels found for S. schenckii s. str., while the low genetic variation of $S$. globosa isolates might be related to a single clinical presentation (fixed cutaneous sporotrichosis), and low virulence profiles related to this species $[11,13]$. However, in Northeast China, clinical cases of sporotrichosis (from fixed cutaneous to disseminated forms), have been attributable exclusively to S. globosa [36]. To confirm or discard our hypothesis, further studies are required, evaluating whether correlations can be found between virulence profiles, species, patient's immunological conditions, and clinical presentation of isolate's source.

Earlier characterization reports of Sporothrix spp. comparing the phenotypic key features for species identification proposed by Marimon et al. [18], and molecular phylogeny methodologies, have shown few disagreements for species identification [13,16,32,37]. In the present study, a high proportion (70\%) of Venezuelan isolates related to sporotrichosis, were not identified according to their phenotype key features (as proposed by Marimon et al. [18]). We discarded a technical problem, since all reference strains were accurately identified by this method (Table 2). So, at least for the Venezuelan isolates here studied, the phenotypic characterization was not useful for species identification.

In our molecular phylogenetic analyses based on CAL and ITS sequences, a strong separation between clinical and environmental clades was evident (Figures 1 and 2), in correspondence with previous reports [6,16-18,33]. Isolate C8213, identified as O. stenoceras was isolated from an immunocompetent patient, supporting the idea that mammal-pathogenicity of Ophiostomales, outside the S. schenckii spp. complex, although highly exceptional [17], still can occur. To the best of our knowledge, this is the first report of O. stenoceras misidentified as causative agent of sporotrichosis in the Americas. Further studies into the mechanisms of opportunistic fungal pathogenesis would help to understand why a harmless fungus, as $O$. stenoceras, could become an infective 


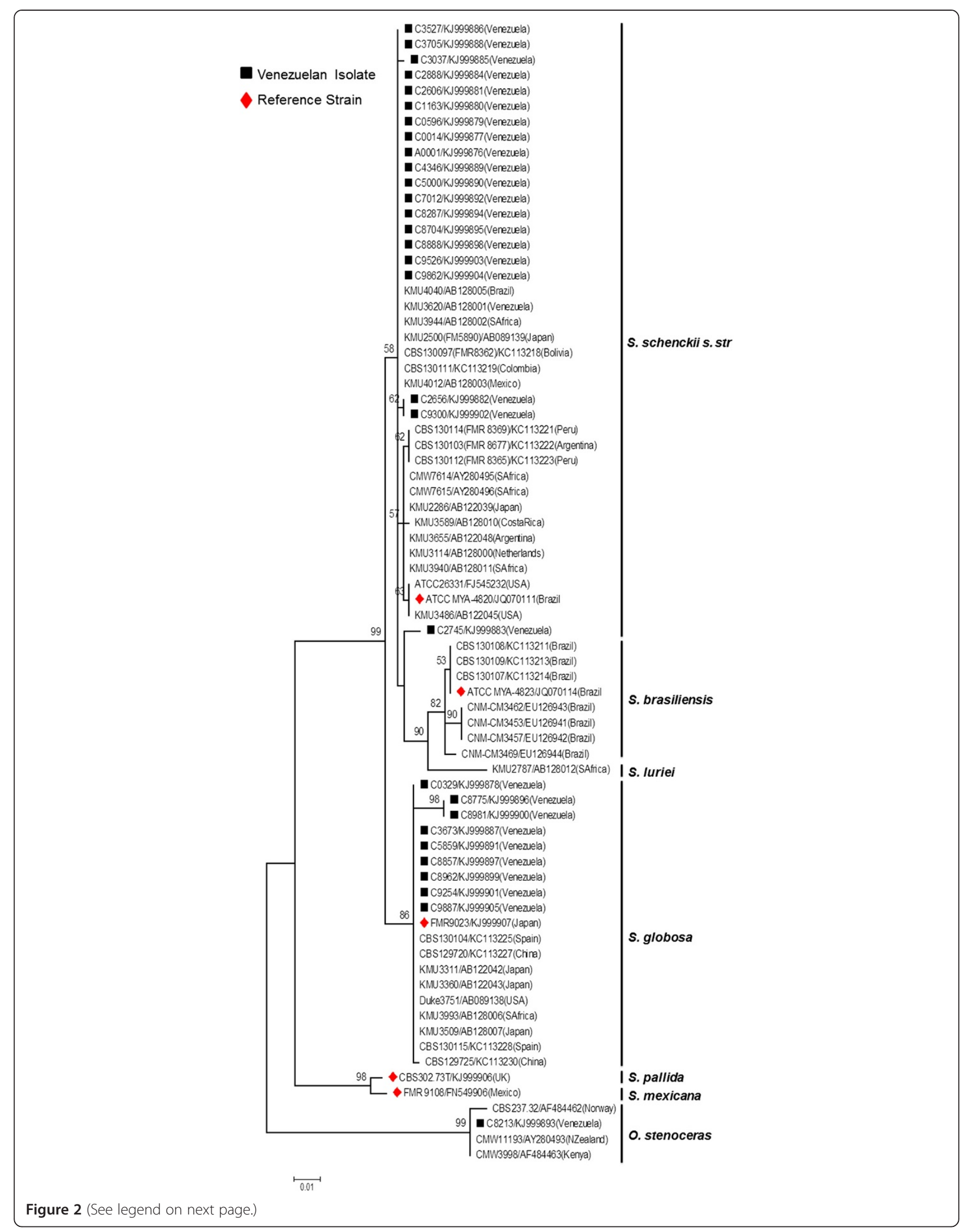


(See figure on previous page.)

Figure 2 Phylogenetic relationships of Sporothrix schenckii complex isolates inferred from ITS sequences. The phylogenetic tree was built with MEGA 5.1, by the Maximum Likelihood method based on the Kimura 2-parameter model. Thirty sequences from this study and forty four from previous reports were used for analysis. Number close to branches represents Bootstraps support values based on 1000 bootstrap replications. GenBank accessions numbers are indicated next to strain code.

Table 2 Isolates characterized by phenotypic and molecular methods included in the study

\begin{tabular}{|c|c|c|c|c|c|c|c|}
\hline \multirow[t]{2}{*}{ Isolate } & \multicolumn{2}{|c|}{$\begin{array}{l}\text { Mean colony diameter }(\mathrm{mm}) \pm S D \\
\text { on PDA during } 21 \text { days }\end{array}$} & \multicolumn{2}{|c|}{ Assimilation test result } & \multirow{2}{*}{$\begin{array}{l}\text { Morphology } \\
\text { of dark sessile } \\
\text { conidia }\end{array}$} & \multirow[t]{2}{*}{$\begin{array}{l}\text { Identification on } \\
\text { physiological tets }\end{array}$} & \multirow{2}{*}{$\begin{array}{l}\text { Identification } \\
\text { on CAL and } \\
\text { ITS sequences }\end{array}$} \\
\hline & $30^{\circ} \mathrm{C}$ & $37^{\circ} \mathrm{C}$ & Sucrose & Raffinose & & & \\
\hline C0014 & $45.5 \pm 0.7$ & $12.0 \pm 0.0$ & + & - & Triangular & $\mathrm{NC}$ & S. schenckii \\
\hline C0329 & $46.5 \pm 2.1$ & $6.5 \pm 0.7$ & + & - & Subglobose & NC & S. globosa \\
\hline C0596 & $53.5 \pm 0.7$ & $23.0 \pm 0.0$ & + & - & Triangular & NC & S. schenckii \\
\hline C1163 & $52.5 \pm 2.1$ & $11.5 \pm 0.7$ & + & + & Triangular & NC & S. schenckii \\
\hline C2606 & $56.0 \pm 0.0$ & $11.5 \pm 0.7$ & + & - & Triangular & NC & S. schenckii \\
\hline C2656 & $52.5 \pm 0.7$ & $13.5 \pm 0.7$ & + & - & Triangular & NC & S. schenckii \\
\hline C2745 & $45.5 \pm 0.7$ & $10.0 \pm 0.0$ & + & - & Triangular & NC & S. schenckii \\
\hline C2888 & $53.5 \pm 0.7$ & $12.5 \pm 0.7$ & + & - & Triangular & NC & S. schenckii \\
\hline C3037 & $57.0 \pm 1.4$ & $15.0 \pm 0.0$ & + & + & Triangular & NC & S. schenckii \\
\hline C3527 & $54.0 \pm 1.4$ & $17.0 \pm 1.4$ & + & + & Triangular & NC & S. schenckii \\
\hline C3673 & $41.5 \pm 0.7$ & $5.5 \pm 0.7$ & + & - & Globose & S. globosa & S. globosa \\
\hline C3705 & $50.0 \pm 1.4$ & $17.0 \pm 1.4$ & + & + & Triangular & S. schenckii & S. schenckii \\
\hline C4346 & $52.0 \pm 1.4$ & $15.0 \pm 0.0$ & + & + & Triangular & $\mathrm{NC}$ & S. schenckii \\
\hline C5000 & $55.5 \pm 0.7$ & $16.5 \pm 0.7$ & + & + & Triangular & NC & S. schenckii \\
\hline C5859 & $38.0 \pm 0.0$ & $4.0 \pm 0.0$ & + & - & Globose & S. globosa & S. globosa \\
\hline C7012 & $58.0 \pm 0.0$ & $22.0 \pm 0.0$ & + & + & Triangular & NC & S. schenckii \\
\hline +C8213 & $25.5 \pm 4.9$ & $12.7 \pm 3.1$ & + & - & NP & NC & O. stenoceras \\
\hline †C8287 & $30.0 \pm 0.0$ & $3.0 \pm 0.0$ & + & - & Triangular & S. globosa & S. schenckii \\
\hline C8704 & $44.5 \pm 0.7$ & $7.0 \pm 1.4$ & + & - & Triangular & $\mathrm{NC}$ & S. schenckii \\
\hline †C8775 & $23.0 \pm 0.0$ & $3.0 \pm 2.8$ & - & - & Subglobose & NC & S. globosa \\
\hline C8857 & $33.5 \pm 0.7$ & $3.0 \pm 2.8$ & + & - & Subglobose & S. globosa & S. globosa \\
\hline C8888 & $52.5 \pm 0.7$ & $14.5 \pm 0.7$ & + & - & Triangular & NC & S. schenckii \\
\hline C8962 & $41.0 \pm 0.0$ & $5.5 \pm 0.7$ & + & - & Subglobose & S. globosa & S. globosa \\
\hline C8981 & $38.0 \pm 0.0$ & $3.0 \pm 0.0$ & + & - & Globose & S. globosa & S. globosa \\
\hline C9254 & $44.5 \pm 0.7$ & $8.0 \pm 0.0$ & + & - & Globose & NC & S. globosa \\
\hline C9300 & $44.5 \pm 0.7$ & $13.5 \pm 0.7$ & + & - & Triangular & NC & S. schenckii \\
\hline C9526 & $42.0 \pm 0.0$ & $13.5 \pm 0.7$ & + & + & Triangular & S. schenckii & S. schenckii \\
\hline C9862 & $52.5 \pm 2.1$ & $12.0 \pm 1.4$ & + & - & Triangular & NC & S. schenckii \\
\hline C9887 & $37.5 \pm 0.7$ & $3.5 \pm 0.7$ & + & - & Globose & S. globosa & S. globosa \\
\hline A0001 & $58.5 \pm 0.7$ & $15.5 \pm 0.7$ & + & - & Triangular & NC & S. schenckii \\
\hline ATCC MYA-4820 & $41.0 \pm 0.0$ & $13.0 \pm 1.4$ & + & + & Triangular & S. schenckii & S. schenckii \\
\hline ATCC MYA-4823 & $43.5 \pm 0.7$ & $13.0 \pm 1.4$ & - & - & Globose & S. brasiliensis & S. brasiliensis \\
\hline CBS $302.73^{\top}$ & $76.5 \pm 0.7$ & $11.0 \pm 0.0$ & + & - & NP & S. pallida & S. pallida \\
\hline FMR 9023 & $33.5 \pm 0.7$ & $5.0 \pm 1.4$ & + & - & Subglobose & S. globosa & S. globosa \\
\hline FMR 9108 & $73.0 \pm 1.4$ & $16.5 \pm 0.7$ & + & + & Ellipsoidal & S. mexicana & S. mexicana \\
\hline
\end{tabular}

Reference strains in bold.

NC, non-conclusive; NP, not present; tlsolates showing atypical phenotypic profiles. 


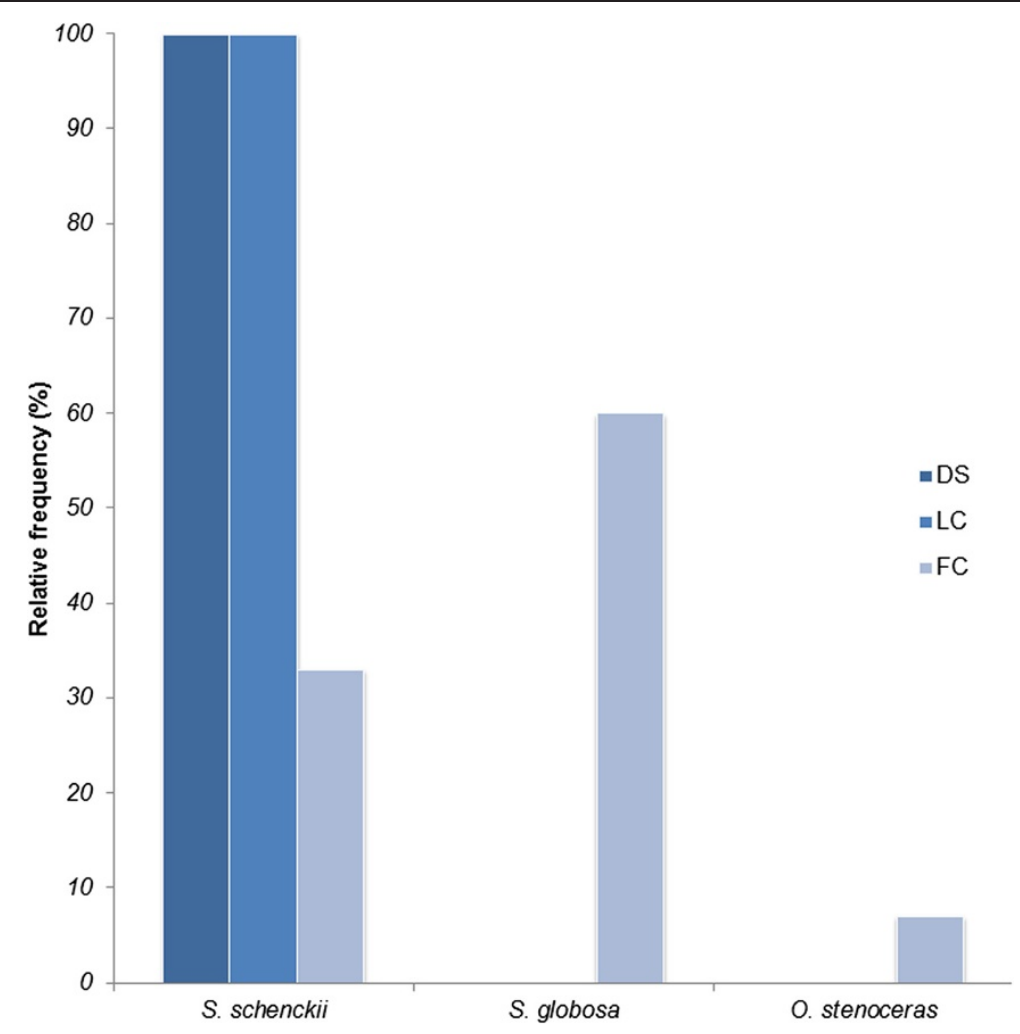

Figure 3 Frequency of clinical forms of sporotrichosis vs. phylogenetic species. DS, disseminated; LC, lymphocutaneous; FC, fixed cutaneous. Information corresponds to clinical cases with available epidemiological data (Table 1).

agent, even for immunocompetent patients. This becomes even more relevant, when we consider the increasing number of reports of Sporothrix infection in immunocompromised patients, mainly the HIV-infected population [1].

Even when selection of the isolates here studied was made trying to cover a broad geographical area of the country, most isolates originated from clinical cases of the coastal region, which can be explained, besides it being a possible ecological niche for the species, to the fact that although this area covers only $3 \%$ of the total surface of the country, it is also the most heavily populated region. Further work with larger data on molecular epidemiology of sporotrichosis in Venezuela is required to verify whether correlation between clinical forms and phylogenetic species exists, and gain better knowledge about S. schenckii species complex spatial distribution in the country.

\section{Conclusions}

The present study shows that sporotrichosis in Venezuela is caused at least by two species: $S$. schenckii s. str. and S. globosa, the latter representing the highest incidence reported in the Americas (30\%). Our results firmly demonstrate that phenotypic key features for species distinction should be used with extreme caution and molecular methods should be always employed. Sporotrichosis clinical forms could be related to genetic variation of $S$. schenckii spp. complex and their virulence profiles. We strongly support application of ITS as a fungal barcoding gene for species distinction of all clinical and environmental clades of Sporothrix, and accidental infective agents within the Ophiostomales.

\section{Competing interests}

The authors declare that they have no competing interests.

\section{Authors' contributions}

Conceived and designed the experiments: EC, MM, GAN-V. Performed the experiments: I-LN, EC, SR-B, Analyzed the data: EC, GAN-V. Contributed reagents/ materials/analysis tools: EC, MM, GAN-V. Wrote the paper: EC, GAN-V. Critically revised the paper: MM, I-LN, SR-B. All authors read and approved the final typescript.

\section{Acknowledgments}

We are grateful to Drs. L. Bezerra (Universidade do Estado do Rio de Janeiro, Brazil), and J. Cano (Tarragona, Spain) for providing references isolates. This work was partially supported by Research Project N ${ }^{\circ} 112$ to GAN-V from Instituto Venezolano de Investigaciones Cientificas (IVIC, Venezuela) and grant PEI2012000827 to EC from Fondo Nacional de Ciencia y Tecnologia (FONACIT, Venezuela).

\section{Author details}

${ }^{1}$ Centro de Microbiología y Biología Celular, Instituto Venezolano de Investigaciones Científicas, Caracas, Venezuela. ${ }^{2}$ Laboratorio de Micología, Instituto de Biomedicina, Caracas, Venezuela. 
Received: 18 November 2014 Accepted: 16 February 2015

Published online: 25 February 2015

\section{References}

1. Lopez-Romero E, Reyes-Montes Mdel R, Perez-Torres A, Ruiz-Baca E, Villagomez-Castro JC, Mora-Montes HM, et al. Sporothrix schenckii complex and sporotrichosis, an emerging health problem. Future Microbiol. 2011;6(1):85-102.

2. Rodrigues AM, de Melo Teixeira M, de Hoog GS, Schubach TM, Pereira SA, Fernandes GF, et al. Phylogenetic analysis reveals a high prevalence of Sporothrix brasiliensis in feline sporotrichosis outbreaks. PLoS Negl Trop Dis. 2013;7(6):e2281.

3. Mackinnon JE, Conti-Diaz IA, Gezuele E, Civila E, da Luz S. Isolation of Sporothrix schenckii from nature and considerations on its pathogenicity and ecology. Sabouraudia. 1969;7(1):38-45

4. Kauffman CA. Sporotrichosis. Clin Infect Dis. 1999;29(2):231-6.

5. Lopes-Bezerra LM, Schubach A, Costa RO. Sporothrix schenckii and sporotrichosis. An Acad Bras Cienc. 2006;78(2):293-308.

6. Romeo O, Scordino F, Criseo G. New insight into molecular phylogeny and epidemiology of Sporothrix schenckii species complex based on calmodulin-encoding gene analysis of Italian isolates. Mycopathologia. 2011:172(3):179-86.

7. Dixon DM, Salkin IF, Duncan RA, Hurd NJ, Haines JH, Kemna ME, et al. Isolation and characterization of Sporothrix schenckii from clinical and environmental sources associated with the largest U.S. epidemic of sporotrichosis. J Clin Microbiol. 1991;29(6):1106-13.

8. Marimon R, Gené J, Cano J, Trilles L, Dos Santos Lazera M, Guarro J. Molecular phylogeny of Sporothrix schenckii. J Clin Microbiol. 2006;44(9):3251-6.

9. Barros MB, de Almeida Paes R, Schubach AO. Sporothrix schenckii and Sporotrichosis. Clin Microbiol Rev. 2011;24(4):633-54.

10. Verma S, Verma GK, Singh G, Kanga A, Shanker V, Singh D, et al. Sporotrichosis in sub-himalayan India. PLoS Negl Trop Dis. 2012;6(6):e1673.

11. Arrillaga-Moncrieff I, Capilla J, Mayayo E, Marimon R, Mariné M, Gené J, et al. Different virulence levels of the species of Sporothrix in a murine model. Clin Microbiol Infect. 2009;15(7):651-5.

12. Fernández-Silva F, Capilla J, Mayayo E, Guarro J. Virulence of Sporothrix luriei in a murine model of disseminated infection. Mycopathologia. 2012;173(4):245-9.

13. Fernandes GF, dos Santos PO, Rodrigues AM, Sasaki AA, Burger E, de Camargo ZP. Characterization of virulence profile, protein secretion and immunogenicity of different Sporothrix schenckii sensu stricto isolates compared with S. globosa and S. brasiliensis species. Virulence. 2013;4(3):241-9.

14. Marimon R, Serena C, Gené J, Cano J, Guarro J. In vitro antifungal susceptibilities of five species of Sporothrix. Antimicrob Agents Chemother. 2008;52(2):732-4.

15. Rodrigues AM, de Hoog GS, de Cassia Pires D, Brihante RS, Sidrim JJ, Gadelha MF, et al. Genetic diversity and antifungal susceptibility profiles in causative agents of sporotrichosis. BMC Infect Dis. 2014;14:219.

16. Rodrigues AM, de Hoog S, de Camargo ZP. Emergence of pathogenicity in the Sporothrix schenckii complex. Med Mycol. 2013;51(4):405-12.

17. Zhou X, Rodrigues A, Feng P, de Hoog GS. Global ITS diversity in the Sporothrix schenckii complex. Fungal Divers. 2014;66(1):153-65.

18. Marimon R, Cano J, Gené J, Sutton DA, Kawasaki M, Guarro J. Sporothrix brasiliensis, S. globosa, and S. mexicana, three new Sporothrix species of clinical interest. J Clin Microbiol. 2007:45(10):3198-206.

19. Marimon R, Gené J, Cano J, Guarro J. Sporothrix luriei: a rare fungus from clinical origin. Med Mycol. 2008;46(6):621-5.

20. Dias NM, Oliveira MM, Santos C, Zancope-Oliveira RM, Lima N. Sporotrichosis caused by Sporothrix Mexicana, Portugal. Emerg Infect Dis. 2011;17(10):1975-6.

21. Morrison AS, Lockhart SR, Bromley JG, Kim JY, Burd EM. An environmental Sporothrix as a cause of corneal ulcer. Medical Mycol Case Reports. 2013;2:88-90.

22. Bommer M, Hutter ML, Stilgenbauer S, de Hoog GS, de Beer ZW, Wellinghausen N. Fatal Ophiostoma piceae infection in a patient with acute lymphoblastic leukaemia. J Med Microbiol. 2009;58(Pt 3):381-5.

23. Mariat F. Adaptation of Ceratocystis to a parasitic life in animals-aquisition of a pathogenicity comparable to Sporothrix schenckii. Sabouraudia. 1971;9(3):191-205.

24. Mata-Essayag S, Delgado A, Colella MT, Landaeta-Nezer ME, Rosello A, Perez de Salazar C, et al. Epidemiology of sporotrichosis in Venezuela. Int J Dermatol. 2013;52(8):974-80.
25. Calcagno AM, Nino-Vega G, San-Blas F, San-Blas G. Geographic discrimination of Paracoccidioides brasiliensis strains by randomly amplified polymorphic DNA analysis. J Clin Microbiol. 1998;36(6):1733-6.

26. O'Donnell K. Molecular phylogeny of the Nectria haematococca-Fusarium solani species complex. Mycologia. 2000;92:919-38.

27. Zhang J, Madden TL. PowerBLAST: a new network BLAST application for interactive or automated sequence analysis and annotation. Genome Res. 1997;7(6):649-56.

28. Duong TA, de Beer ZW, Wingfield BD, Wingfield MJ. Phylogeny and taxonomy of species in the Grosmannia serpens complex. Mycologia. 2012;104(3):715-32.

29. Tamura K, Peterson D, Peterson N, Stecher G, Nei M, Kumar S. MEGA5: molecular evolutionary genetics analysis using maximum likelihood, evolutionary distance, and maximum parsimony methods. Mol Biol Evol. 2011;28(10):2731-9.

30. Nei M. Molecular evolutionary genetics. New York: Columbia University Press; 1987.

31. Librado P, Rozas J. DnaSP v5: a software for comprehensive analysis of DNA polymorphism data. Bioinformatics. 2009;25(11):1451-2.

32. Oliveira MM, Almeida-Paes R, Muniz MM, Gutierrez-Galhardo MC, ZancopeOliveira RM. Phenotypic and molecular identification of Sporothrix isolates from an epidemic area of sporotrichosis in Brazil. Mycopathologia. 2011;172(4):257-67.

33. Rodrigues AM, de Hoog G, Zhang Y, de Camargo ZP. Emerging sporotrichosis is driven by clonal and recombinant Sporothrix species. Emerg Microbes Infect. 2014;3:e32.

34. Madrid H, Cano J, Gené J, Bonifaz A, Toriello C, Guarro J. Sporothrix globosa, a pathogenic fungus with widespread geographical distribution. Rev Iberoam Micol. 2009;26(3):218-22

35. Sasaki AA, Fernandes GF, Rodrigues AM, Lima FM, Marini MM, Dos SFL, et al. Chromosomal polymorphism in the Sporothrix schenckii complex. PLoS One. 2014;9(1):e86819.

36. Yu X, Wan Z, Zhang Z, Li F, Li R, Liu X. Phenotypic and molecular identification of Sporothrix isolates of clinical origin in Northeast China. Mycopathologia. 2013;176(1-2):67-74.

37. Ottonelli Stopiglia CD, Magagnin CM, Castrillon MR, Mendes SD, Heidrich D, Valente $\mathrm{P}$, et al. Antifungal susceptibilities and identification of species of the Sporothrix schenckii complex isolated in Brazil. Med Mycol. 2014;52(1):56-64.

\section{Submit your next manuscript to BioMed Central and take full advantage of:}

- Convenient online submission

- Thorough peer review

- No space constraints or color figure charges

- Immediate publication on acceptance

- Inclusion in PubMed, CAS, Scopus and Google Scholar

- Research which is freely available for redistribution

Submit your manuscript at www.biomedcentral.com/submit 